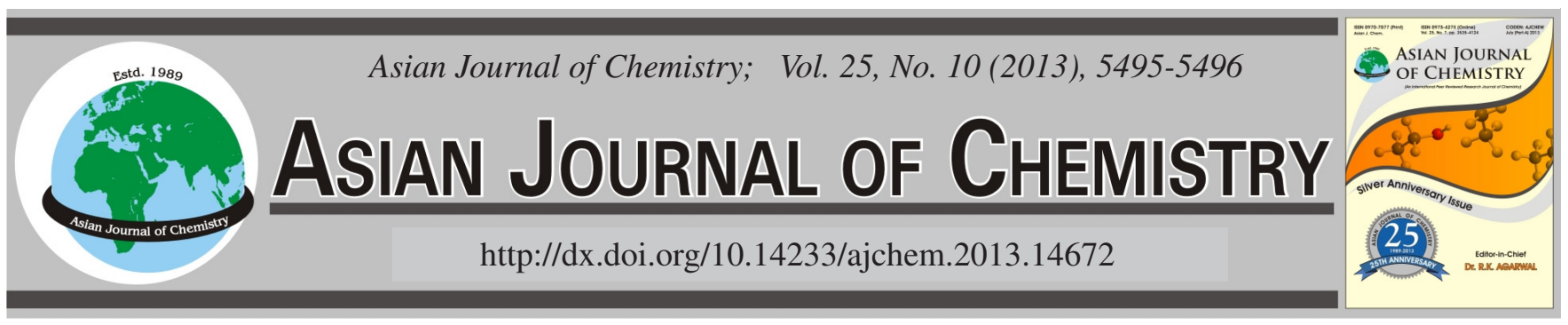

NOTE

\title{
Synthesis and Characterization of 4,4'-Dimethoxy-1,1'- [(butane-1,4-diyldioxy)bis(nitrilomethylidyne)]dibenzene
}

\author{
YU-J JE DING ${ }^{1, *}$, YANG $_{\text {WANG }}^{2}$ and JIAN-GANG GAO ${ }^{1}$
}

${ }^{1}$ College of Biochemical Engineering, Anhui Polytechnic University, Wuhu 241000, P.R. China

${ }^{2}$ Material Examination Department, State Intellectual Property Office, Beijing 100088, P.R. China

*Corresponding author: E-mail: yujieding123@163.com

\begin{abstract}
The compound 4,4'-dimethoxy-1,1'-[(butane-1,4-diyldioxy)bis(nitrilomethylidyne)]dibenzene with the molecular formula $\mathrm{C}_{20} \mathrm{H}_{24} \mathrm{~N}_{2} \mathrm{O}_{4}$ was synthesized by the reaction of 4-methoxybenzaldehyde with 1,4-bis(aminooxy)butane in ethanol medium and characterized structurally by X-ray crystallography. Intermolecular C-H...O hydrogen bonding is observed between $\mathrm{C}-\mathrm{H}$ of methoxy groups and $\mathrm{O}$ atom from methoxy groups of the neighboring compound molecules. It is noted that the distances between the nearest benzene rings, which are parallel to that of another molecule, are about $2.466(2) \AA$ in the crystal structure, exhibiting strong intermolecular $\pi$ - $\pi$ stacking interactions, which forms two-dimensional structures of the title compound.
\end{abstract}

Key Words: 4,4'-Dimethoxy-1,1'-[(butane-1,4-diyldioxy)bis(nitrilomethylidyne)]dibenzene, Synthesis, Crystal structure.

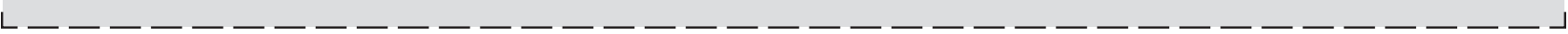

$\mathrm{N}_{2} \mathrm{O}_{2}$ type ligands such as salen-type bisoxime compound are easily obtained by the reaction of salicylaldehyde with diamines, coordinate to $d$-block transition metals in a tetradentate fashion to afford stable mononuclear ${ }^{1}$, dinuclear ${ }^{2}$, trinuclear $^{3}$, tetranuclear ${ }^{4}$ and octanuclear ${ }^{5}$ complexes. Herein, a bisoxime compound, 4,4'-dimethoxy-1,1'-[(butane-1,4-diyldioxy)bis(nitrilomethylidyne)]dibenzene was designed and synthesized, which may be useful as a build block for larger supramolecules ${ }^{6,7}$.

4-Methoxybenzaldehyde was purchased from Alfa Aesar and was used without further purification. 1,4-Bis(aminooxy)butane was synthesized according to a method reported earlier ${ }^{1,7}$. The other reagents and solvents were analytical grade reagents from Tianjin Chemical Reagent Factory. C, H and N analyses were carried out with a GmbH VariuoEL V3.00 automatic elemental analyzer. X-ray single crystal structure was determined on a Bruker Smart 1000 CCD area detector. Melting points were measured by the use of a microscopic melting point apparatus made in Beijing Taike Instrument Limited Company and the thermometer was uncorrected.

4,4'-Dimethoxy-1,1'-[(butane-1,4-diyldioxy)bis(nitrilomethylidyne)]dibenzene was synthesized according to a method reported earlier ${ }^{7}$. To an ethanolic solution $(8 \mathrm{~mL})$ of 4-methoxybenzaldehyde (408.44 mg, $3.0 \mathrm{mmol})$ was added an ethanol ( $8 \mathrm{~mL})$ solution of 1,4-bis(aminooxy)butane (180.23 $\mathrm{mg}, 1.50 \mathrm{mmol})$. The mixture solution was stirred at $328 \mathrm{~K}$ for $3 \mathrm{~h}$. The precipitate was filtered, washed successively with ethanol/hexane (1:4) and hexane, respectively. The product was dried under vacuum and purified with recrystallization from ethanol to yield $284.77 \mathrm{mg}$ of the title compound. Yield, $79.9 \%$. m.p. 367-368 K. Anal. calcd. (\%) for $\mathrm{C}_{20} \mathrm{H}_{24} \mathrm{~N}_{2} \mathrm{O}_{4}$ : C, 67.40; H, 6.79; N, 7.86. Found (\%): C, 67.28; H, 7.00; N, 7.84 .

Colourless block-shaped single crystals suitable for $\mathrm{X}$-ray diffraction studies were obtained after $c a$. 2 months by slow evaporation at room temperature from a chloroform solution of 4,4'-dimethoxy-1,1'-[(butane-1,4-diyldioxy)-bis(nitrilomethylidyne)]dibenzene.

X-Ray structure determination: The single crystal of the present compound, with approximate dimensions of 0.30 $\mathrm{mm} \times 0.28 \mathrm{~mm} \times 0.27 \mathrm{~mm}$ was placed on a Bruker Smart 1000 diffractmeter equipped with Apex CCD area detector. The diffraction data were collected using a graphite monochromated $\mathrm{MoK}_{\alpha}$ radition $(\lambda=0.71073 \AA)$ at 298(2) K. The structure was solved by using the program SHELXS-97 and Fourier difference techniques and refined by full-matrix leastsquares method on $\mathrm{F}^{2}$ using SHELXL-97. Details of the data collection and refinements of the title compound are given in Table-1. The non-hydrogen atoms were refined anisotropically. Hydrogen atoms were added theoretically. CCDC: 693775.

$\mathrm{X}$-ray crystallographic analysis revealed the crystal structure of the present compound. The structure is shown in Fig. 1. Selected bond distances and angles are listed in Table- 2 . 
TABLE-2

SELECTED BOND LENGTHS (̊̊) AND ANGLES $\left(^{\circ}\right)$ FOR THE TITLE COMPOUND

\begin{tabular}{|c|c|c|c|c|c|}
\hline BOND & LENGTHS & BOND & LENGTHS & BOND & LENGTHS \\
\hline $\mathrm{N}(1)-\mathrm{C}(3)$ & $1.265(7)$ & $\mathrm{C}(1)-\mathrm{C}(2)$ & $1.465(8)$ & $C(5)-C(6)$ & $1.382(7)$ \\
\hline $\mathrm{N}(1)-\mathrm{O}(1)$ & $1.422(6)$ & $\mathrm{C}(2)-\mathrm{C}(2)^{\# 1}$ & $1.480(12)$ & $C(6)-C(7)$ & $1.386(7)$ \\
\hline $\mathrm{O}(1)-\mathrm{C}(1)$ & $1.413(7)$ & $\mathrm{C}(3)-\mathrm{C}(4)$ & $1.453(7)$ & $\mathrm{C}(7)-\mathrm{C}(8)$ & $1.383(7)$ \\
\hline $\mathrm{O}(2)-\mathrm{C}(7)$ & $1.366(6)$ & $\mathrm{C}(4)-\mathrm{C}(5)$ & $1.380(7)$ & $\mathrm{C}(8)-\mathrm{C}(9)$ & $1.376(7)$ \\
\hline $\mathrm{O}(2)-\mathrm{C}(10)$ & $1.436(7)$ & $C(4)-C(9)$ & $1.383(7)$ & & \\
\hline BOND & ANGLES & BOND & ANGLES & BOND & ANGLES \\
\hline $\mathrm{C}(3)-\mathrm{N}(1)-\mathrm{O}(1)$ & $111.1(5)$ & $C(5)-C(4)-C(9)$ & $118.0(5)$ & $\mathrm{O}(2)-\mathrm{C}(7)-\mathrm{C}(6)$ & $115.0(5)$ \\
\hline $\mathrm{C}(1)-\mathrm{O}(1)-\mathrm{N}(1)$ & 110.1(4) & $\mathrm{C}(5)-\mathrm{C}(4)-\mathrm{C}(3)$ & $123.0(5)$ & $\mathrm{C}(8)-\mathrm{C}(7)-\mathrm{C}(6)$ & $119.4(5)$ \\
\hline $\mathrm{C}(7)-\mathrm{O}(2)-\mathrm{C}(10)$ & $118.2(5)$ & $C(9)-C(4)-C(3)$ & $118.9(5)$ & $\mathrm{C}(9)-\mathrm{C}(8)-\mathrm{C}(7)$ & $119.8(5)$ \\
\hline $\mathrm{O}(1)-\mathrm{C}(1)-\mathrm{C}(2)$ & $110.4(5)$ & $C(4)-C(5)-C(6)$ & $121.2(5)$ & $\mathrm{C}(8)-\mathrm{C}(9)-\mathrm{C}(4)$ & $121.7(5)$ \\
\hline$C(1)-C(2)-C(2)^{\# 1}$ & $115.0(7)$ & $C(5)-C(6)-C(7)$ & $119.9(5)$ & & \\
\hline $\mathrm{N}(1)-\mathrm{C}(3)-\mathrm{C}(4)$ & $121.6(5)$ & $\mathrm{O}(2)-\mathrm{C}(7)-\mathrm{C}(8)$ & $125.6(5)$ & & \\
\hline
\end{tabular}

TABLE-1

CRYSTAL DATA AND REFINEMENT PARAMETERS FOR THE TITLE COMPOUND

\begin{tabular}{ll}
\hline Empirical formula & $\mathrm{C}_{20} \mathrm{H}_{24} \mathrm{~N}_{2} \mathrm{O}_{4}$ \\
Formula weight & 356.41 \\
Temperature & $298(2) \mathrm{K}$ \\
Wavelength & $0.71073 \AA$ \\
Crystal system & $\mathrm{Pbca}$ \\
Space group & Orthorhombic \\
Cell dimensions & $\mathrm{a}=7.1042(10) \AA, \mathrm{b}=6.1951(8)$ \\
& $\AA, \mathrm{c}=43.340(3) \AA$ \\
Volume & $1907.4(4) \AA^{3}$ \\
$Z$ & 4 \\
Density (calculated) & $1.241 \mathrm{mg}^{3} \mathrm{~m}^{3}$ \\
Absorption coefficient & $0.087 \mathrm{~mm}^{-1}$ \\
$F(000)$ & 760 \\
Index ranges & $-8 \leq \mathrm{h} \leq 8,-7 \leq \mathrm{k} \leq 7,-38 \leq 1 \leq 51$ \\
Reflections collected & $8685 / 1657[R(\mathrm{int})=0.0778]$ \\
Independent reflections & 906 \\
Data/restraints/parameters & $1657 / 0 / 119$ \\
Goodness of fit indicator & 1.076 \\
$\mathrm{R}[\mathrm{I}>2 \sigma(\mathrm{I})]$ & $\mathrm{R}_{1}=0.0532, \mathrm{wR}_{2}=0.0819$ \\
Largest diff. peak and hole & 0.270 and $-0.338 \mathrm{e} . \AA^{-3}$ \\
\hline
\end{tabular}

The molecule is disposed about a crystallographic centre of symmetry and the molecule adopts an extended conformation where the two 4-methoxybenzaldoxime moieties are separated from each other. The oxime groups and phenolic groups have anti-conformations and there are four weak $\mathrm{C}-\mathrm{H}$...O intermolecular hydrogen bonds, C10-H10B...O2 (d(C10-H10B $)=$ $0.962 \AA, \mathrm{d}(\mathrm{H} 10 \mathrm{~B} \ldots \mathrm{O} 2)=2.590(1) \AA \mathrm{d}(\mathrm{C} 10 \ldots \mathrm{O} 2)=3.389(2)$ $\left.\AA, \angle \mathrm{C} 10-\mathrm{H} 10 \mathrm{~B} \ldots \mathrm{O} 2=127.38(2)^{\circ}\right)$ in the crystal structure ${ }^{8,9}$.

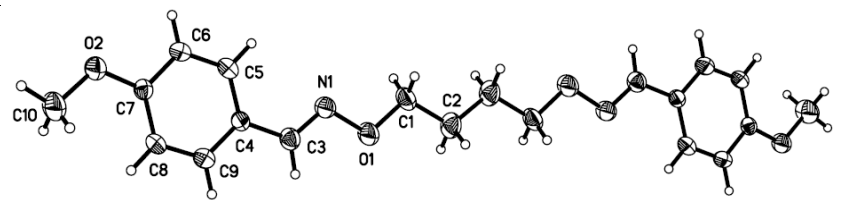

Fig. 1. Molecule structure of the title compound with atom numbering scheme. Displacement ellipsoids for non-hydrogen atoms are drawn at the $30 \%$ probability level
It is noted that the distances between the nearest benzene rings, which are parallel to that of another molecule, are about $2.466(2) \AA$ in the crystal structure, exhibiting very significantly strong intermolecular pai-pai stacking interactions, which forms two-dimensional structures of the title compound.

\section{ACKNOWLEDGEMENTS}

This work was supported by Foundation for the Youth Scholars of Educational Commission of Anhui Province, China (No. 2011SQRL075).

\section{REFERENCES}

1. W.K. Dong and Y.J. Ding, Cryst. Res. Technol., 43, 321 (2008).

2. W.K. Dong, J.H. Feng and X.Q. Yang, Synth. React. Inorg. Met.-Org. Nano-Met. Chem., 37, 189 (2007).

3. S. Akine, T. Taniguchi and T. Nabeshima, Inorg. Chem., 43, 6124 (2004).

4. W.K. Dong, J.H. Feng, L. Wang, L. Xu, L. Zhao and X.Q. Yang, Transition Met. Chem., 32, 1101 (2007b).

5. S. Akine, W.K. Dong and T. Nabeshima, Inorg. Chem., 45, 4677 (2006).

6. S.S. Sun, C.L. Stem, S.T. Nguyen and J.T. Hupp, J. Am. Chem. Soc., 126, 6314 (2004).

7. (a). W.K. Dong, Y.X. Sun, Y.P. Zhang, L. Li, X.N. He and X.L. Tang, Inorg. Chim. Acta., 362, 117 (2009); (b). W.K. Dong, J.G. Duan, Y.H. Guan, J.Y. Shi and C.Y. Zhao, Inorg. Chim. Acta, 362, 1129 (2009); (c). W.K. Dong, X.N. He, H.B. Yan, Z.W. Lv, X. Chen, C.Y. Zhao and X.L. Tang, Polyhedron, 28, 1419 (2009); (d). W.K. Dong, G. Wang, S.S. Gong, J.F. Tong, Y.X. Sun and X.H. Gao, Transition Met. Chem., 37, 271 (2012); (e). W.K. Dong, Y.X. Sun, C.Y. Zhao, X.Y. Dong and L. Xu, Polyhedron, 29, 2087 (2010); (f). W.K. Dong and J.G. Duan, J. Coord. Chem., 61, 781 (2008b).

8. H.L. Wu, F. Jia, F. Kou, B. Liu, J.K. Yuan and Y. Bai, Transition Met. Chem., 36, 847 (2011).

9. H.L. Wu, K.T. Wang, F. Kou, F. Jia, B. Liu, J.K. Yuan and Y. Bai, J. Coord. Chem., 64, 2676 (2010). 